\title{
Open-Cellular Alumina Foams with Hierarchical Strut Porosity by Ice Templating: A Thickening Agent Study
}

\author{
Kathleen Dammler ${ }^{1, *}$, Katja Schelm ${ }^{1}$, Ulf Betke ${ }^{1} \mathbb{(}$, Tobias Fey $^{2,3}{ }^{\mathbb{D}}$ and Michael Scheffler ${ }^{1}$ \\ 1 Institute for Materials and Joining Technology, Otto-von-Guericke University Magdeburg, 39106 Magdeburg, Germany; \\ Katja.schelm@gmx.de (K.S.); ulf.betke@ovgu.de (U.B.); m.scheffler@ovgu.de (M.S.) \\ 2 Department of Materials Science and Engineering, Institute of Glass and Ceramics, Friedrich-Alexander \\ Universität Erlangen-Nürnberg (FAU), 90762 Erlangen, Germany; tobias.fey@fau.de \\ 3 Frontier Research Institute for Materials Science, Nagoya Institute of Technology, Gokiso-cho, Showaku, \\ Nagoya 466-8555, Japan \\ * Correspondence: kathleen.dammler@ovgu.de
}

Citation: Dammler, K.; Schelm, K.; Betke, U.; Fey, T.; Scheffler, M. Open-Cellular Alumina Foams with Hierarchical Strut Porosity by Ice Templating: A Thickening Agent Study. Materials 2021, 14, 1060. https://doi.org/10.3390/ma14051060

Academic Editor: Thomas Fiedler

Received: 21 December 2020

Accepted: 16 February 2021

Published: 24 February 2021

Publisher's Note: MDPI stays neutral with regard to jurisdictional claims in published maps and institutional affiliations.

Copyright: (c) 2021 by the authors. Licensee MDPI, Basel, Switzerland. This article is an open access article distributed under the terms and conditions of the Creative Commons Attribution (CC BY) license (https:// creativecommons.org/licenses/by/ $4.0 /)$.

\begin{abstract}
Alumina replica foams were manufactured by the Schwartzwalder sponge replication technique and were provided with an additional strut porosity by a freeze-drying/ice-templating step prior to thermal processing. A variety of thickeners in combination with different alumina solid loads in the dispersion used for polyurethane foam template coating were studied. An additional strut porosity as generated by freeze-drying was found to be in the order of $\sim 20 \%$, and the spacings between the strut pores generated by ice-templating were in the range between $20 \mu \mathrm{m}$ and $32 \mu \mathrm{m}$. In spite of the lamellar strut pore structure and a total porosity exceeding $90 \%$, the compressive strength was found to be up to $1.3 \mathrm{MPa}$. Combining the replica process with freeze-drying proves to be a suitable method to enhance foams with respect to their surface area accessible for active coatings while preserving the advantageous flow properties of the cellular structure. A two-to-threefold object surface-to-object volume ratio of 55 to $77 \mathrm{~mm}^{-1}$ was achieved for samples with $30 \mathrm{vol} \%$ solid load compared to $26 \mathrm{~mm}^{-1}$ for non-freeze-dried samples. The freeze-drying technique allows the control of the proportion and properties of the introduced pores in an uncomplicated and predictable way by adjusting the process parameters. Nevertheless, the present article demonstrates that a suitable thickener in the dispersion used for the Schwartzwalder process is inevitable to obtain ceramic foams with sufficient mechanical strength due to the necessarily increased water content of the ceramic dispersion used for foam manufacturing.
\end{abstract}

Keywords: foams; replica; ice templating; alumina; freeze casting

\section{Introduction}

Ceramic foams with an open pore structure are commonly used, e.g., as filters, supports for heterogeneous catalysts, heat exchangers and silencers [1-5]. Often, a high specific surface area and high mechanical stability are required for these applications. The manufacturing is typically carried out by a sponge replication technique, known as the Schwartzwalder process [6], and the resulting ceramic foams possess hollow struts. Those cellular materials own a specific surface area of 1-2 $\mathrm{m}^{2} \mathrm{~g}^{-1}$, which is comparably low [7] for application as catalyst carriers, for instance. The specific surface area has been increased in various studies, for instance, by coating them with a high surface area washcoat [8] or using a porous alumina powder [9].

For those applications where active coatings are a component of the foam strut surface, a higher surface area may be of advantage. As an example, adsorption heat storage or adsorption heat pump materials are addressed [10,11]. Accessibility to the inner struts, a higher specific surface area by a controlled introduction of pores into the strut material or a combination of both may significantly increase the specific surface area, which, in turn, may lead to a higher load with an active coating material, such as zeolites or Metal 
organic frameworks (MOFs) [11] and thus expand the range of possible applications. A potential processing route to access the inner strut surface and to increase the strut porosity is the combination of the Schwartzwalder process with the freeze-drying technique, as shown in literature for hydroxyapatite-ceramics (with coating of 75 ppi Polyurethane (PU) templates) [12], $\mathrm{SiO}_{2}$ ceramics [13] and alumina ceramics (with a coating of 20 ppi PU templates) [14]. Freeze-drying is a common tool [3,15-17] to introduce oriented porosity in bulk ceramics $[1,18,19]$, with bioceramics also among them [20].

The feasibility of the combination of the ceramic-foam replica process with the freeze technique was recently demonstrated for alumina foams by Schelm et al. [14]. While the replica process leads to a cellular porosity with pores in the range of the cellular template cells/windows (e.g., for 20 ppi templates in the mm-range), the hollow struts (for 20 ppi in the range of $100 \mu \mathrm{m}$ ) and the remaining bulk porosity after sintering, an additional porosity with lamellar-shaped pores was introduced by a freeze-drying step subsequently after foam template coating. The spacing of the pores and the lamellar thickness after thermal processing was shown to be a function of the cooling rate and the cooling temperature, as the freezing agent water was used [14].

Figure 1 illustrates the combination of both processing methods. In the first step, a polyurethane (PU) sponge is coated with a water-based alumina particle containing dispersion; excess dispersion is removed by gentle squeezing (Figure 1, top left); this is referred to as the Schwartzwalder process, polymer sponge method or replica process [6]. This coating develops the dense stuts with a triangular void, whereas the strut material itself can contain residual porosity (depending on sintering conditions), inside, the struts are hollow as a consequence of the template burnout. In case of freeze-drying, the struts possess additional lamellar pore spacings. During the freeze-drying process, ice crystals form, leaving behind a lamellar shape in the freezing material (Figure 1, center right) [21]; the sublimation (Figure 1, center bottom) is driven by a decrease in pressure and temperature.

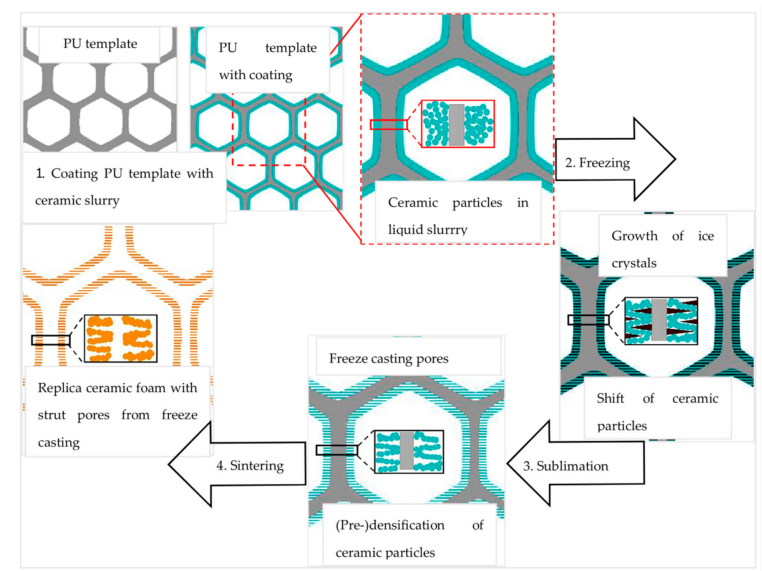

Figure 1. Illustration scheme of the experimental procedure for manufacturing alumina freeze-dried replica foams.

The resulting porosity is controllable by the variation of the processing parameters such as the solid content of the coating suspension, the freezing temperature, the amount and type of additives (amongst others sucrose, trehalose, $\mathrm{D}(+)$ - trehalose dehydrate, glycerol, ethanol, sodium chloride) [22]. Within the freezing process, control of nucleation of the ice crystals, which occurs at nucleation seeds, and their growth, is important for the pore spacing control $[14,15,20,23,24]$. Fast cooling rates lead to an increased magnitude of supercooling ahead of the solidifying interface and as a consequence a decrease of the tip radius of the ice crystals, thereby a finer microstructure is achieved [18,21].

Besides water, camphene can be used as a freezing vehicle, due to its ability to form dendritic structures during freezing, and it sublimes at room temperature, which 
means that no specific sublimation equipment is necessary. Further details can be found elsewhere [25-30].

The final step is the thermal processing, which consists of the PU burn out and the sintering, which is carried out after PU burn out or after PU coating, freeze-drying, PU burn out in this specific case (Figure 1, bottom left).

In [14] was stated that there is a conflict between both processing routes: The replica method needs high solid loads to achieve a moderate to high compressive strength of high-porosity materials. In contrast, the freeze-drying process is well controllable with low solid loads. This, in turn, complicates the handling of samples prior to sintering or leads to a non-acceptable low compressive strength. While in our previous work [14] the influence of the freezing temperature (and thus the cooling rate) and the solid load was studied on the porosity and the compressive strength, in this paper we varied the type and amount of the thickening agent as a processing aid in the coating dispersion; the solid load was similar to that in Schelm et al. in ref. [14].

\section{Materials and Methods}

\subsection{Ceramic Foam Processing}

The alumina powder used in this study was CT3000SG with an average particle size of $0.67 \mu \mathrm{m}$ (Almatis $\mathrm{GmbH}$, Ludwigshafen, Germany). As a deflocculant, Dolapix CE64 (Zschimmer and Schwarz GmbH and Co. KG, Lahnstein, Germany) was added to the powder. In the next step, a dispersion/solution of a thickener, see Table 1, was added and the mixture was stirred with a spatula and subsequently mixed with a planetary centrifugal blender (Model ARE-250, Thinky Corporation, Tokyo, Japan) for $15 \mathrm{~min}$ at $2000 \mathrm{rpm}$. After this mixing step, a polyvinyl alcohol binder (Optapix PA 4G, Zschimmer and Schwarz GmbH and Co. KG, Lahnstein, Germany) was added and the mixing step was repeated with the same mixing duration and rotational speed. Thickening agents used in this work were:

- guar gum, G (Guarkernmehl, Arche Naturprodukte GmbH, Hilden, Germany)

- $\quad$ modified methyl cellulose (wallpaper paste), WP (Spezialkleister, Wilckens Farben $\mathrm{GmbH}$, Glückstadt, Germany)

- methyl cellulose, MC (160,000 $\mathrm{g} \mathrm{mol}^{-1}$, Carl Roth GmbH\&Co. KG, Karlsruhe, Germany) and

- $\quad$ starch (potato) S (sauce binder, Mondamin, Unilever Deutschland GmbH, Hamburg, Germany).

Table 1. Concentration of thickening agents in water.

\begin{tabular}{cc}
\hline Thickening Agent & Amount (g) in 25 mL Water \\
\hline guar gum (G) & 0.675 \\
modified methyl cellulose (wallpaper paste) (WP) & 1.5 \\
methyl cellulose (MC) & 1.5 \\
potato starch (S) & 3.125 \\
\hline
\end{tabular}

Regarding the different characteristics of the thickeners, a diverse behavior in the ceramic dispersion could be expected, not only in terms of the thickening effect, which is high for guar gum and starch versus low to high for methyl cellulose, but also in terms of the template coating capability (film formation high for starch and methyl cellulose, but not for guar gum). This is likely to be reflected in the results. The properties of the thickeners used are summarized in Table 2.

Thickener formulations from the food and glue industries were used due to their long-term availability and constant quality over several batches of these products and their homogeneous consistency when dispersed/dissolved in water. 
Table 2. Characteristics of thickening agents used (after [31]).

\begin{tabular}{|c|c|c|c|c|c|c|}
\hline Thickener & Source & $\begin{array}{c}\text { Chemical } \\
\text { Composition }\end{array}$ & Shear Stability & Gelation & $\begin{array}{c}\text { Film } \\
\text { Formation }\end{array}$ & $\begin{array}{c}\text { Thickening } \\
\text { Effect }\end{array}$ \\
\hline guar gum & $\begin{array}{l}\text { endosperm of } \\
\text { seed }\end{array}$ & $\begin{array}{l}\text { polysaccharide } \\
\text { of D-mannose } \\
\text { and D-galactose }\end{array}$ & shear thinning & no & low & high \\
\hline starch & $\begin{array}{l}\text { seed extracts } \\
\text { (germs, roots) }\end{array}$ & $\alpha$-D-glucose & $\begin{array}{c}\text { low after } \\
\text { gelation, } \\
\text { irreversible } \\
\text { viscosity loss }\end{array}$ & upon heating & high & high \\
\hline $\begin{array}{c}\text { methyl } \\
\text { cellulose }\end{array}$ & $\begin{array}{l}\text { wood pulp or } \\
\text { cotton linters }\end{array}$ & $\begin{array}{c}\text { linear polymer } \\
\text { of } \beta \text {-D-glucose } \\
\text { with }\left(\mathrm{CH}_{3}\right)- \\
\text { substituents }\end{array}$ & $\begin{array}{l}\text { shear-thinning } \\
\text { with } \\
\text { re-thickening } \\
\text { effect (after } \\
\text { rest-time), gels } \\
\text { are very } \\
\text { thixotropic }\end{array}$ & $\begin{array}{l}\text { reversible } \\
\text { gelation upon } \\
\text { heating }\end{array}$ & high & low to high \\
\hline wallpaper paste & & & mixture of starch a & d methyl cellulose & & \\
\hline
\end{tabular}

As water-based dispersions, two different solid loads with alumina ( $30 \mathrm{vol} \%$ and $40 \mathrm{vol} \%$ ) were investigated in combination with the thickening agents as shown in Table 2. The compositions of the dispersions are listed in Table 3.

Table 3. Dispersion compositions for polyurethane (PU) foam coating.

\begin{tabular}{ccccc}
\hline Dispersion Type & \multicolumn{2}{c}{ 30 vol\% Dispersion } & \multicolumn{2}{c}{ 40 vol\% Dispersion } \\
\hline Material & $\mathrm{wt} \%$ & $\mathrm{vol} \%$ & $\mathrm{wt} \%$ & vol\% \\
$\mathrm{Al}_{2} \mathrm{O}_{3}$ powder & 61.64 & 29.08 & 70.88 & 38.42 \\
distilled water and thickening agent & 36.51 & 68.04 & 26.99 & 58.26 \\
according to Table 1 & 0.92 & 1.44 & 1.06 & 1.66 \\
deflocculant Dolapix CE 64 & 0.92 & 1.44 & 1.06 & 1.66 \\
binder Optapix PA 4G & &
\end{tabular}

Prior to template coating with the different dispersions, viscosity measurements of these ceramic dispersions were carried out in a plate-plate-viscometer (MCR-301, Anton Paar GmbH, Graz, Austria). The shear stress was measured for shear rates from $0.1 \mathrm{~s}^{-1}$ to $100 \mathrm{~s}^{-1}$. These measurements were carried out in order to a) to study the influence of the different thickeners on the dispersion formulation and $b$ ) to adjust the dispersion viscosity for a proper coating/to ensure reproducible coating conditions. During the viscosity measurements, the measuring system was covered to reduce the water evaporation from the dispersion.

The PU template pieces $(15 \times 15 \times 20) \mathrm{mm}^{3}$ for coating (Koepp Schaum $\mathrm{GmbH}$, Oestrich-Winkel, Germany, 20 ppi) were separately dipped into the dispersions. After withdrawal from the dispersion, they were gently squeezed to remove additional dispersion from the coated foam template and to open still closed-cell windows. The samples were weighted in the wet state to guarantee almost the same weight for all samples $(\sim 1.6 \mathrm{~g}$ for each coated sample). After coating, the samples were put into a freezing compartment of a household freezer at $-20{ }^{\circ} \mathrm{C}$ and hold for $24 \mathrm{~h}$ to generate the ice crystals responsible for the pore formation within the foam struts. For comparison, a certain number of coated foam templates were dried at ambient conditions $\left(20^{\circ} \mathrm{C}\right.$, atmospheric pressure); this was carried out with 12 to 15 pieces of foam for each type of thickener and $30 \mathrm{vol} \%$ as well $40 \mathrm{vol} \%$ particle load. After freezing the foams were placed in a freeze-dryer (Alpha 1-4 LDPlus, BETA, 1-16 LMC-2, Martin Christ Gefriertrocknungsanlagen GmbH, Osterode am Harz, Germany), the condenser temperature was set to $-55^{\circ} \mathrm{C}$ and a pressure of $0.1 \mathrm{mbar}$ was adjusted. Freeze-drying was carried out for $24 \mathrm{~h}$. 
After freeze processing, thermal treatment processes were carried out. In a first heating step, the template was removed at $400{ }^{\circ} \mathrm{C}$ in air in a circulating air furnace (KU 40/04/A, THERMCONCEPT Dr. Fischer GmbH, Bremen, Germany) with a heating rate of $3 \mathrm{~K} \mathrm{~min}^{-1}$ and a three hours dwell time. In the last step, the foams were sintered in a chamber furnace (Modell HTL 04/18, THERMCONCEPT Dr. Fischer GmbH and Co. KG, Bremen, Germany) at $1650{ }^{\circ} \mathrm{C}$ in air with a dwelling time of three hours at $600{ }^{\circ} \mathrm{C}$ and at peak temperature; heating and cooling rates were set to $3 \mathrm{~K} \mathrm{~min}^{-1}$. Weight analysis after freeze-drying and sintering showed for each piece of foams a weight of $1.2 \mathrm{~g}$ for the templates coated with the $30 \mathrm{vol} \%$ dispersion and $1.3 \mathrm{~g}$ for those coated with the $40 \mathrm{vol} \%$ dispersion. This, however, makes a comparison of resulting properties easier.

In summary, sixteen different foam series with approximately 12 samples of each series, eight series without and eight series with an additional freeze-drying step, were manufactured.

\subsection{Micro- and Macrostructure Analysis}

The strut porosity of the ceramic foams was determined by the Archimedes' principle according to DIN EN ISO 1183 [32]. A hydrostatic scale (Cubis, Sartorius, Göttingen, Germany) with an accuracy of $0.01 \mathrm{mg}$ for weight and buoyancy measurements for the open strut porosity determination was used, see also Schelm et al. [14].

The determination of the total foam porosity was carried out by measuring the geometric volume of a sample (total rectangular bloc foam volume) of $2.5-3.2 \mathrm{~cm}^{3}$ with a caliper and the weight of the samples after sintering (new Classic MF Model: ML204/01, Mettler Toledo Intl. Inc, Columbus, OH, USA).

For scanning in an X-ray microcomputertomograph ( $\mu-\mathrm{CT})$ selected foams were fixed separately on the sample holder of the $\mu$-CT (Nanotom S, GE Sensing and Inspection Technologies, Wunstorf, Germany). The voltage was adjusted to $50 \mathrm{kV}$, the tube current was set to $110 \mu \mathrm{A}$, and the distance between the sample holder and X-ray tube and detector was defined to obtain a voxel size of $3.5 \mu \mathrm{m}^{3}$ for scanning a small volume element of a foam sample (approx. $3-4 \mathrm{~mm}^{3}$ in size) with high resolution. The reconstruction of the data was performed with the software package Phoenix Datos IX 2.0 (GE Sensing and Inspection Technologies, Wunstorf, Germany). The lamellar pore spacing distribution and the material lamellae thickness distribution were determined from the $\mu$-CT reconstruction data with the software CT Analyzer 1.18 (Skyscan/Bruker microCT, Kontich, Belgium). The average pore spacing and material lamellae thickness was determined from the obtained histograms by fitting one (or a set of) Gauss function(s). More details on the calculation procedure are available in Betke et al. and Schelm et al. [14,33].

Scanning electron micrographs were generated with a scanning electron microscope (SEM, XL30 ESEM-FEG, FEI/Phillips, Hillsboro, OR, USA). Volume elements, as well as embedded and ground cross-sections of the samples, were analyzed. The volume elements of samples were mounted on the sample holder with carbon paste (PLANO Leit C, Plano $\mathrm{GmbH}$, Wetzlar, Germany), resin-embedded samples were glued on the sample holder of the SEM with silver paste, both kinds of samples were sputter-coated with gold.

\subsection{Compressive Strength Measurements}

The compressive strength was measured with a TIRATEST 2825 (TIRA GmbH, Schalkau, Germany). For the measurement of the samples thin squared pieces of cardboard were placed under and over the to-be-measured foam pieces of the size $\left(2.5-3.2 \mathrm{~cm}^{3}\right)$ to guarantee a proper force transfer to the entire area of the foam. The cross-head speed used was $2 \mathrm{~mm} \mathrm{~min}-1$; ten species of each sample series were measured and the values were averaged.

\section{Results and Discussion}

$\mathrm{Al}_{2} \mathrm{O}_{3}$ replica foams with increased open strut porosity were manufactured, as already reported previously for varying the freezing temperature [14]. The foam microstructure and, as a consequence, the mechanical properties are influenced-amongst others-by the thickening agent as well as the solid content of the ceramic dispersion. 


\subsection{Rheological Behavior of Ceramic Dispersions}

Viscosity measurements were carried out to obtain alumina dispersions with rheological properties suitable for PU template coating; this means a shear-thinning behavior and the desired viscosity at a given shear rate are necessary $[33,34]$. Another issue is the water content necessary for freeze-drying [14]. Figure 2a shows the shear stress-shear rate curves of the alumina/water system (with additives: binder, deflocculant, ref. to Table 3) with $30 \mathrm{vol} \%$ alumina and $40 \mathrm{vol} \%$ alumina, which are suitable for freeze-drying driven generation of pores, as shown in previous works $[14,18]$. In addition, the flow behavior for the plain thickening agent/water system (without additions, Figure $2 b$ ) was analyzed. It was shown before in literature that the thickening agents chosen (forming a gel-network with water) are commonly used in ceramic processing (for example starch [35-47], guar gum $[14,48]$, methyl cellulose $[49,50])$. Starch is well known from starch consolidation casting to act as a thickening agent and pore former.


Figure 2. Shear stress vs. shear rate: (a) of alumina dispersions ( $30 \mathrm{vol} \%$ and $40 \mathrm{vol} \%$ ) in water with the additives binder and deflocculant (solid lines represent a fit via the Herschel-Bulkley-model); (b) thickening agents dissolved in water (solid lines represent a fit via the Power-Law model), see Table 1.

The flow curves of the investigated alumina dispersions could not be approximated adequately with the commonly used Bingham model, which describes a Newtonian flow behavior above a given yield stress $\tau_{0}$ [51]. However, the shear stress-shear rate plots of the investigated alumina-water dispersions (Figure 2a) were fitted with the Herschel-Bulkley model (Equation (1) [52]. This model combines a yield stress $\tau_{0}$ with a shear-thinning flow behavior for stress values exceeding $\tau_{0}$, see Equation (1).

$$
\tau=\tau_{0}+K \gamma^{\cdot n}
$$

The measured shear stress-shear rate data were fitted starting at a shear rate of $1 \mathrm{~s}^{-1}$, due to the wall slip effect present for the investigated dispersions [53,54], which would falsify the approximation, as described in the literature [55]. The alumina dispersions show a yield stress $\tau_{0}$ that is increasing for an increasing alumina solid content (1.2 Pa for $30 \mathrm{vol} \%$ $\mathrm{Al}_{2} \mathrm{O}_{3} ; 7.5 \mathrm{~Pa}$ for $40 \mathrm{vol} \% \mathrm{Al}_{2} \mathrm{O}_{3}, 15.22 \mathrm{~Pa}$ for $43 \mathrm{vol} \% \mathrm{Al}_{2} \mathrm{O}_{3}$ [49]).

In contrast, the flow curves of the thickening agent-water mixtures show a flow behavior in accordance with the Power Law, which describes a Non-Newtonian behavior without a yield stress $\tau_{0}(=0)$ [56]. All dispersions show a shear-thinning behavior, as indicated by the flow index $\mathrm{n}<1$ ( 0.43 for $30 \mathrm{vol} \% \mathrm{Al}_{2} \mathrm{O}_{3} ; 0.36$ for $40 \mathrm{vol} \% \mathrm{Al}_{2} \mathrm{O}_{3} ; 0.36$ for MC; 0.35 for WP; 0.23 for G; 0.32 for $S)$ [14,49], which is important for a successful coating (especially entering of dispersion into template pores) of PU templates during the sponge replication process $[33,57,58]$.

Figure 3 represents the viscosity-shear rate plots of the ceramic dispersions used in this study, which possess also a shear-thinning behavior, as found in the literature, especially for dispersions containing methyl cellulose and guar gum $[48,50,59,60]$. As the 
shear rate, which is applied to the dispersions by squeezing the PU template during coating is unknown, the viscosity at a shear rate of $100 \mathrm{~s}^{-1}$ was selected for further discussion [50]. This value is in the range of shear rates in typical extrusion processes which are 10-1000 s $\mathrm{s}^{-1}$, ref. [54]. As shown in Figure 3, the viscosity at a shear rate of $100 \mathrm{~s}^{-1}\left(\eta_{100}\right)$ for the dispersion containing methylcellulose $\left(\eta_{100}=12.9\right.$ Pa s$)$ is approximately one order of magnitude higher compared to dispersions containing guar gum $\left(\eta_{100}=1.07 \mathrm{~Pa} s\right)$ and starch $\left(\eta_{100}=1.35 \mathrm{~Pa} \mathrm{~s}\right)$, the viscosity with wallpaper paste $\left(\eta_{100}=3.43 \mathrm{~Pa} \mathrm{~s}\right)$ is between those values.



Figure 3. Viscosity vs. shear rate of ceramic dispersions with 30 vol.\% solid load for coating of Polyurethane (PU) templates.

Generally, the viscosity decreases for an increasing shear rate for all dispersions, and the flow behavior is in a range suitable for the manufacturing of ceramic foams by the replica technique $[33,34,58,59]$.

\subsection{Macro- and Microstructure of Sintered Foams}

The total foam porosity, as determined from the geometrical dimensions and the foam's weight, was approximately $90 \%$ for all samples. Discrete values are discussed below.

The open and closed strut porosity results as measured with the water immersion test (Archimedes method DIN EN 623-2, [9,14]) are shown in Figure 4.
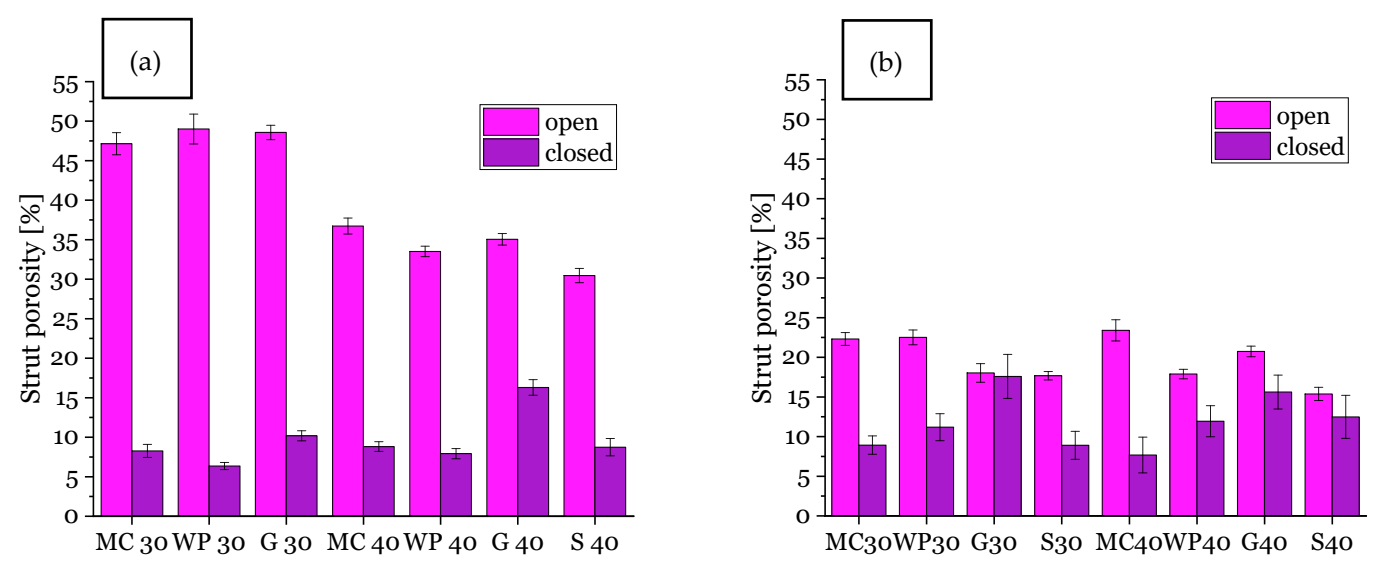

Figure 4. Open and closed strut porosity of samples with $30 \mathrm{vol} \%$ (30) and $40 \mathrm{vol} \%$ (40) solid load in ceramic dispersion, (a): with additional strut porosity from freeze-drying, (b): without additional strut pores/conventionally dried samples; $\mathrm{MC}=$ methylcellulose, $\mathrm{WP}=$ wallpaper paste, $\mathrm{G}=$ guar gum, $\mathrm{S}=$ Starch. 
The total strut porosity of the replica foams with additional strut pores from freezedrying is increased compared to foams dried at ambient conditions. The reason for this is the evaporation of water during the drying at ambient conditions in contrast to keeping water inside of the ceramic coating via a transformation into ice crystals and subsequent sublimation converting the ice crystals into lamellar pores. This process is directional and tends to particle movement (pre-densification), as the ice crystals expand during their formation - that is the reason for lamellar-shaped pores in the struts of the foams [18,21] and partly a moderate compressive strength, which will be discussed below.

In particular, the open strut porosity increased by applying the freeze casting technique for replica foams with $30 \mathrm{vol} \%$ alumina content compared to samples with $40 \mathrm{vol} \%$ alumina dispersion content, reaching an average strut porosity of $48 \%$ (for comparison: $20 \%$ for samples dried at ambient conditions/non-freeze-drying). This indicates a complete passage of the freeze casting lamellae through the foam struts. If that would not be the case, closed porosity would increase instead (as shown in SEM micrograph for samples with guar gum, Figure $5 \mathrm{a}$ and increased closed strut porosity, Figure 4a from entrapped air).
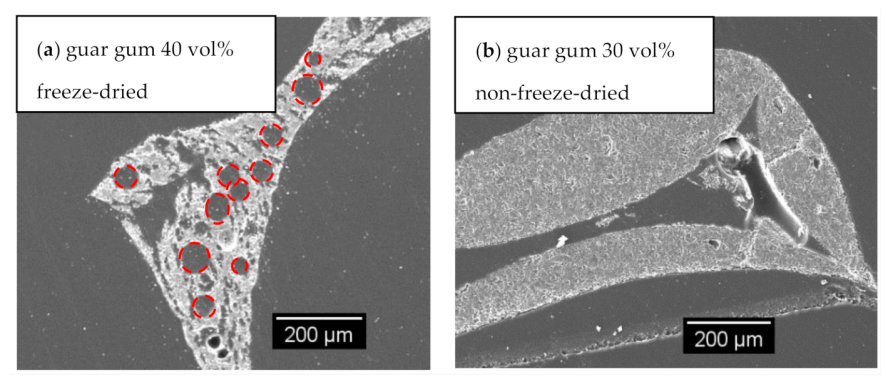

Figure 5. SEM micrographs of sintered foam samples (a) sample with guar gum, 40 vol.-\% solid content and freeze-drying pores (holes from air bubbles marked with red circles), (b) sample with guar gum, 30 vol.- $\%$ solid content, conventionally dried at room temperature (pls. refer: [14]).

The SEM micrographs are also in good agreement with these results-a high number of the pore spacings are open to the outside of the strut surface in foams with a decreased solid content of the coating slurry (Figure 6).

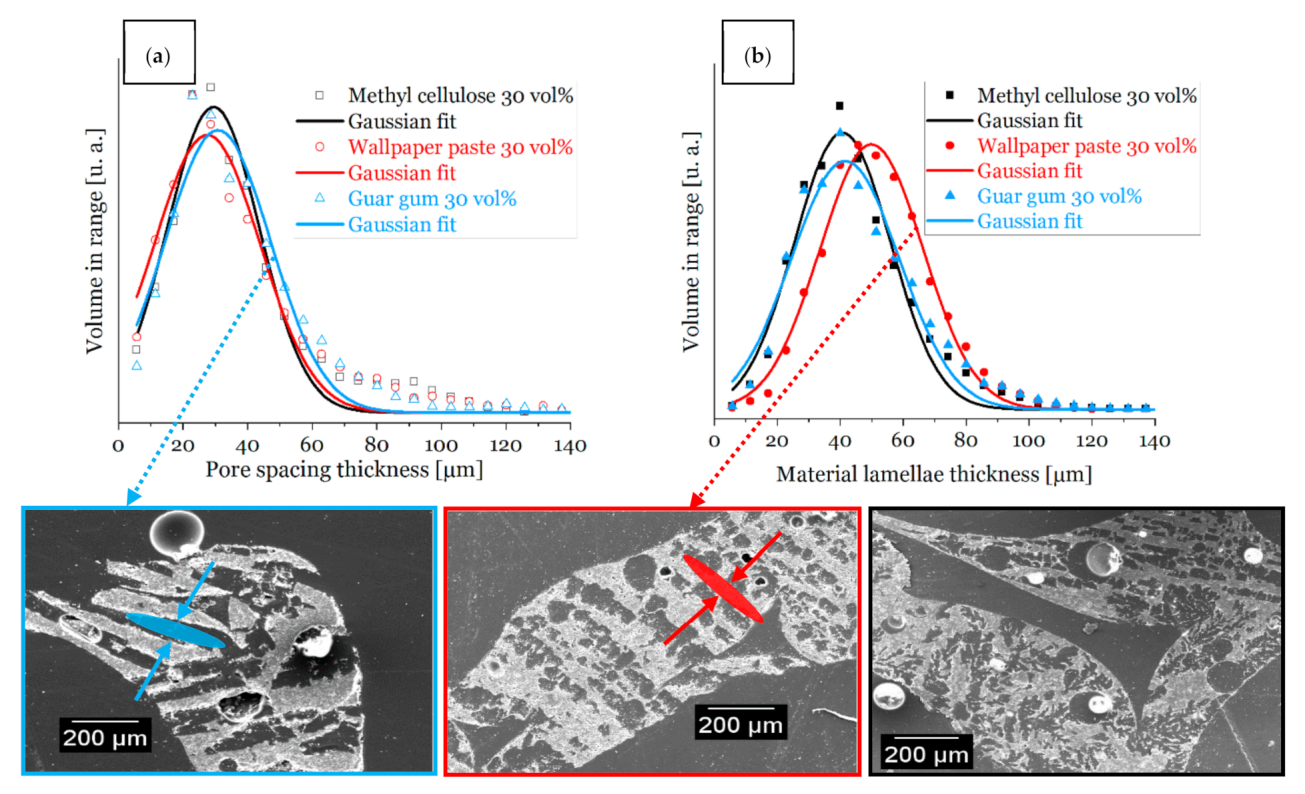

Figure 6. Distributions of the width of material lamella and pore spacings of sintered foam samples from dispersions with $30 \mathrm{vol} \%$ solid load measured by $\mu$-CT and SEM images; (a): distribution of the pore spacing (a) and material lamella thickness (b) of sample struts, respectively; (bottom): SEM micrographs of cross-sections of sintered foams; pore spacings and material lamellae exemplary marked with arrows; $\mathrm{MC}=$ methylcellulose, $\mathrm{WP}=$ wallpaper paste, $\mathrm{G}=$ guar gum. 
The widths of the material lamellae and the pore spacing were calculated from $\mu$ $\mathrm{CT}$ data collected on one selected sample per sample series according to the procedure described in $[14,33]$.

For a dispersion solid content of $30 \mathrm{vol} \%$ (Figure 6) the material lamella thickness for all thickening agents is fairly in the same range (between $43 \mu \mathrm{m}$ and $53 \mu \mathrm{m}$ ). For an increased solid content in the ceramic dispersion (40 vol\%, Figure 7) the distribution of the material lamella thickness is broader and more varying, those values are in a range between $53 \mu \mathrm{m}$ and $95 \mu \mathrm{m}$. This is a consequence of a higher amount of ceramic particles in the dispersion $[3,14]$. As expected, the thickness of the pore spacing shows an inverse behavior and increases for lower solid content of the ceramic dispersion (for $30 \mathrm{vol} \%$ solid load between $29 \mu \mathrm{m}$ and $33 \mu \mathrm{m}$ ), due to increased water content, and, consequently, a broader ice front during freezing $[3,14]$.


Figure 7. Distributions of the width of material lamella and pore spacings of sintered foam samples from dispersions with 40 vol.- $\%$ solid load measured by $\mu-C T$; distribution of the (a) pore spacing thickness and (b) material lamella thickness of sample struts from sintered foam samples, respectively.Freeze-dried replica foams with starch flour as a thickening agent made from $30 \mathrm{vol} \%$ alumina dispersions broke during PU burnout; their stability was insufficient, most likely due to the high amount of lamellar pores within the foam structure.

For samples made of $40 \mathrm{vol} \%$ alumina dispersions (Figures 7 and 8), the lamellae pore thickness decreases in comparison to samples from dispersions with a reduced solid load of $30 \mathrm{vol} \%$. There is one exception: samples with guar gum as a thickener, justified by round voids, ref. Figures 5 and $8 \mathrm{a}$ ), which is in good accordance with the results of previous work [14].

A smaller lamella pore thickness leads in general to an increase of the compressive strength [14,22], as shown within Section 3.2, and in Figure 9. SEM micrographs (Figure 6) demonstrate the lamellar shape of the pores obtained from freeze casting and for all thickening agents the direction of single lamellar pores is non-oriented (Figure 6) originating in non-directional freezing, which should be a benefit for compressive strength of the as-produced samples with additional strut pores.

Summarizing this, it can be stated that the amount, respectively the increased fraction of open strut porosity according to the water immersion test, (ref. Figure 4) and size of the pores, increased for a decreased solid content ( $30 \mathrm{vol} \%$ alumina dispersions). These findings are in accordance with the literature [14,61]. The temperature gradient, or freezing velocity, respectively, was constant during processing within this work, therefore differences in the thickness of the material lamellae/pore spacings originate in the solid-water ratio and the thickening agent also with respect to the flow behavior, as described in the following section (gas bubbles).

Another issue is bubble-shaped voids within the microstructure of replica foams with pores from freeze-drying - especially for guar gum as a thickener: Figure 5 a shows a cross-section of a replica foam strut with additional porosity from freeze-drying. Visible 
voids in Figures 5 and 8 a originate from air bubbles during the template coating. These spherical pores are most likely caused by gas bubbles being present in the dispersion. For the dispersions containing $40 \mathrm{vol}$ solids, which have a significantly higher viscosity and yield stress compared to the dispersions with $30 \mathrm{vol} \%$ solid loading, the gas bubbles can not escape from the still wet dispersion after coating the PU template. This is especially caused by the increased yield stress (7.5 Pa vs. 1.2 Pa). The share of closed strut porosity determined with the Archimedes method increased for samples from guar gum dispersion (especially for $40 \mathrm{vol} \%$ solid load samples) compared to samples with the same solid load of $40 \mathrm{vol} \%$ and other thickeners (methyl cellulose and wallpaper paste), as shown in Figure 4. This is in good agreement with the SEM micrograph of Figure 6a and images of $\mu C T$-measurement in Figure 8. Figure 5b [14]) shows the microstructure of a replica foam dried at ambient conditions, the thickening agent was guar gum, too. No lamellar material or lamellar pore spacings or bubble-shaped voids were found.

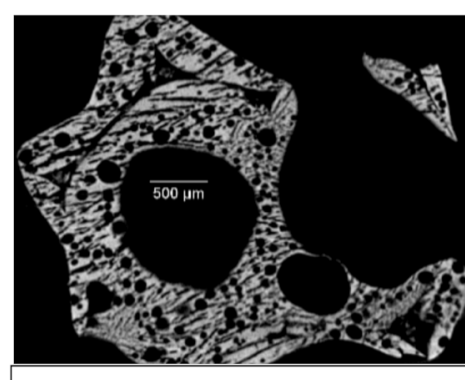

(a) guar gum



(b) methyl cellulose

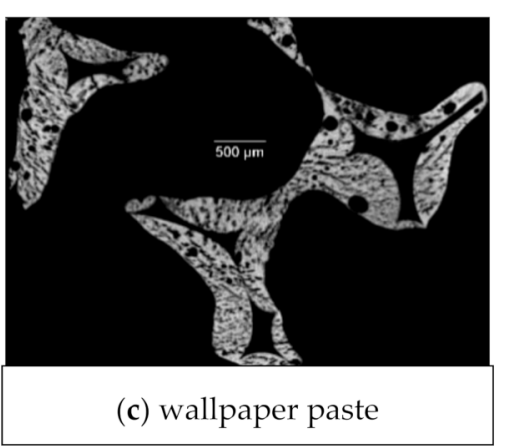

Figure 8. $\mu \mathrm{CT}$-Images of samples with $40 \mathrm{vol} \%$ solid content (a) guar gum, (b) methylcellulose, (c) wallpaper paste.3.2. Microstructure of Dried Samples (Coating Quality).

As shown in Figure 9, the dispersion coating behavior onto the PU template strutsSEM micrographs show the critical part, sharp edge of the PU foam strut-varies for different thickening agents. As a consequence, the compressive strength of foams was influenced, as it was shown for methylcellulose in ref. [50].


Figure 9. SEM micrographs of (a) original Polyurethane (PU) template, (b-d) coated PU templates with ceramic dispersions with $30 \mathrm{vol} \%$ solid load and different thickeners (b) Starch, (c) Methyl cellulose, (d) Wallpaper paste, dried at room temperature (before sintering-PU-template is still intact).

\subsection{Compressive Strength}

The compressive strength values are shown in Figure 10a for samples with pores from freeze-drying and in Figure 10b for samples dried at ambient conditions at room temperature (without additional pores from freeze-drying).

As shown in Figure 10, the compressive strength and the relative density of the samples increase with increasing solid content in the ceramic dispersion used for sample preparation, whereby the sample weight kept constant during template coating, independent of the 
solid content. Therefore, the fraction of ceramic particles within the wet dispersion coated on the template is higher for higher solid content dispersions and, as a consequence, the relative density of the foams made therefrom is higher as well [14].

The surface-to-volume ratio for the samples with additional pores due to freezedrying is increased for all foams. The surface-to-volume ratio decreases for samples with higher solid content and is still slightly increased compared to samples that were dried at room temperature.
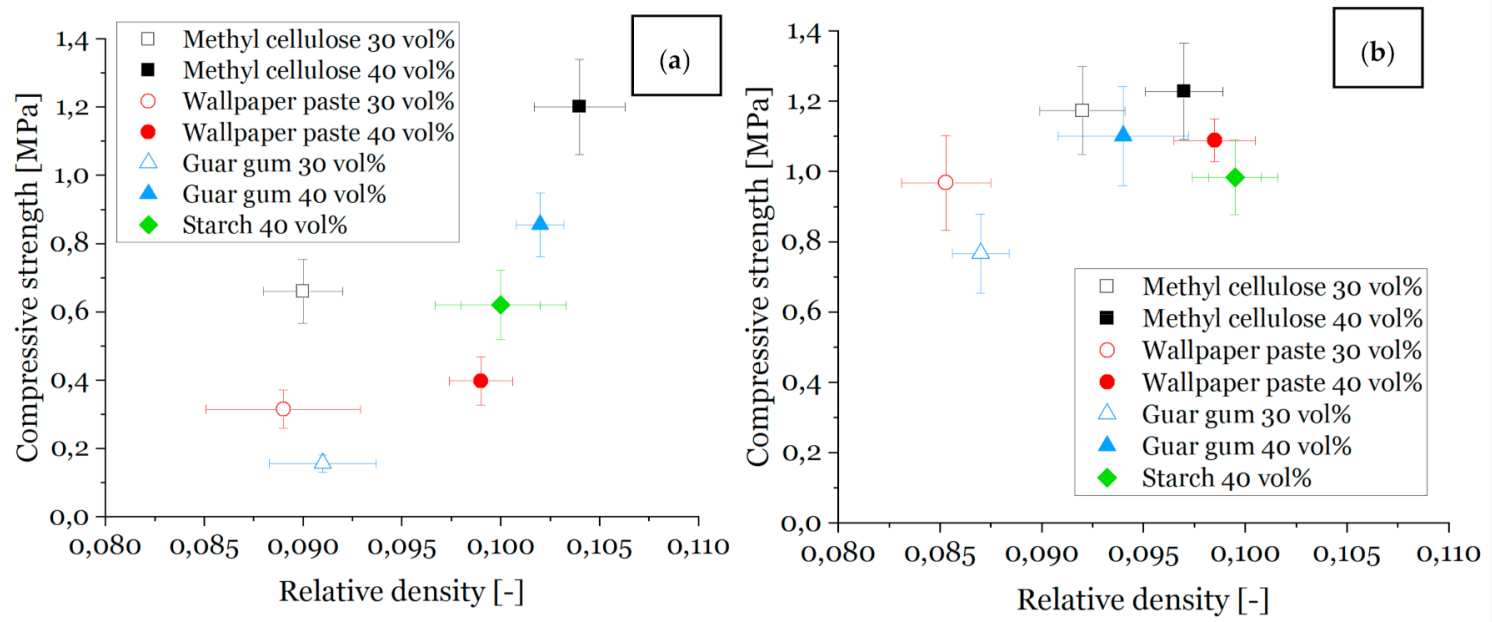

Figure 10. Compressive strength vs. relative density of all sample series and solid loads, sintered at $1650{ }^{\circ} \mathrm{C}$; (a): samples with freeze casting, (b): samples dried at room temperature.

The values of relative density lie in a range of $8 \%$ to $11 \%$ for all samples and those values are similar for different foam series, e.g., for $30 \mathrm{vol} \%$ freeze-dried with thickener methyl cellulose foams, a total foam porosity ranging from $90.8 \%$ to $91.2 \%$ is observed, and for wallpaper paste foams with the same conditions, the porosity ranges from $90.7 \%$ to $91.5 \%$. Hence, the compressive strength of these materials compares well.

Furthermore, the compressive strength is higher for a higher solid content [14] and for foams without freeze casting, as the number of defects in the strut material is lower [14,22]. The same reason counts for the highest compressive strength values found for the samples with methylcellulose as a thickener: the viscosity of the methylcellulose containing dispersion was the highest, cf. Figure 3, and gives therefore the best conditions for a homogeneous and nearly defect-free template coating, cf. also Figure 8. [50] The compressive strength for the foams made from the dispersions with methylcellulose and $30 \mathrm{vol} \%$ solid content are in the range of $0.3 \mathrm{MPa}$ to $0.9 \mathrm{MPa}$. Consequently, this is an improvement compared with the strength results of, e.g., freeze-dried foams with guar gum as a thickener with the same solid load (0.1 MPa) [14]. Considering the Weibull moduli (Table 4), it is noticeable that the samples investigated in this article achieved values comparable to foams without additional pores and the thickener methyl cellulose [51] or increased solid content in the ceramic dispersion [62].

Table 4. Weibull-modulus m (Visual-XSel 14.0) and object-surface-to-object-volume ratio of investigated samples.

\begin{tabular}{cccccccc}
\hline Sample & MC 30 & WP 30 & GG 30 & MC 40 & WP40 FC/RT & $\begin{array}{c}\text { GG 40 } \\
\text { FC/RT }\end{array}$ & S 40 FC/RT \\
& FC/RT & FC/RT & FC/RT & FC/RT & & $3.38 / 4.653$ \\
Weibull & $3.511 / 4.967$ & $2.544 / 3.07$ & $2.76 / 3.313$ & $6.087 / 4.185$ & $2.885 / 8.610$ & $5.258 / 3.833$ \\
R $^{2}$ & $0.9806 / 0.9163$ & $0.9299 / 0.9013$ & $0.9407 / 0.9625$ & $0.8870 / 0.9314$ & $0.9258 / 0.9013$ & $0.9357 / 0.9511$ & $0.9445 / 0.9209$ \\
Obj. & & & & & & \\
$\begin{array}{c}\text { Surf./Obj. } \\
\text { Vol. }\end{array}$ & 70.8 & 51.5 & $69.6 / 26.3$ & 27.8 & 30.2 & 48.3 & \\
\hline
\end{tabular}


For a $40 \mathrm{vol} \%$ dispersion solid content, the compressive strength for samples from methylcellulose and guar gum is between $0.8 \mathrm{MPa}$ and $1.3 \mathrm{MPa}$.

\section{Conclusions}

It was shown that the Schwartzwalder process for the manufacturing of open-cellular alumina foams in combination with freeze-drying of as-coated foam templates is feasible for a number of different thickening agents and for a variation of the alumina particle solid load in the coating dispersion. A solid load of $30 \mathrm{vol} \%$ leads to a higher total strut porosity as well as broader pore spacings and thinner material lamellae in the foam struts compared to a solid load of $40 \mathrm{vol} \%$; these characteristics underwent only a small variation when different thickeners were used.

In spite of the high porosity and the lamellar structure of the foam struts, a compressive strength of up to $1.3 \mathrm{MPa}$ at a total strut porosity of $46 \%$ and an overall total porosity between $90 \%$ and $91 \%$ was reached for foams processed with methyl cellulose as a thickener. The use of guar gum as a thickener, however, resulted in the formation of additional bubbleshaped pores, which, in turn, reduced the compressive strength and increased the share of the closed strut porosity (especially for higher solid loads). This work shows important basics regarding the combination of both methods (replica and freezing technique) and highlights their potential for usage as carriers for active materials.

Author Contributions: Conceptualization, K.D., K.S. and U.B.; methodology, K.D. and K.S.; software, K.D., T.F. and U.B.; validation, U.B., M.S. and T.F.; formal analysis, U.B. and M.S.; investigation, K.D. and K.S.; resources, K.D. and K.S.; data curation, K.D.; writing-original draft preparation, K.D.; writing-review and editing, U.B., T.F. and M.S.; visualization, K.D.; supervision, U.B. and M.S..; project administration, M.S.; funding acquisition, M.S. All authors have read and agreed to the published version of the manuscript.

Funding: This work was funded by the European Structural Investment Funds under the code and number MEMoRIAL 6410032013.

Institutional Review Board Statement: Not applicable.

Informed Consent Statement: Not applicable.

Data Availability Statement: All relevant data are mentioned in the publication.

Acknowledgments: This work was carried out in the frame of a scholarship from the International Graduate School MEMoRIAL, which is funded by the European Structural Investment Funds under the code and number MEMoRIAL 641003 2013; this is grateful acknowledged. The authors wish to thank Diethard Kürschner for his help with the freeze-dryer and Michael Schwidder for viscosity measurements; both from the Faculty for Process Engineering of the Otto-von-Guericke-University, Magdeburg, Germany.

Conflicts of Interest: The authors declare no conflict of interest. The funders had no role in the design of the study; in the collection, analyses, or interpretation of data; in the writing of the manuscript, or in the decision to publish the results.

\section{References}

1. Fukasawa, T.; Deng, Z.-Y.; Ando, M.; Ohji, T.; Goto, Y. Pore structure of porous ceramics synthesized from water-based slurry by freeze-dry process. J. Mater. Sci. 2001, 36, 2523-2527. [CrossRef]

2. Zaman, E.; Keles, O. Open Cell Aluminum Foams Produced by Polymer Impregnation Method. Acta Phys. Pol. A 2014, 125, 445-448. [CrossRef]

3. Deville, S. Freeze-Casting of Porous Ceramics: A Review of Current Achievements and Issues. Adv. Eng. Mater. 2008, 10, 155-169. [CrossRef]

4. Soltani, N.; Simon, U.; Bahrami, A.; Wang, X.; Selve, S.; Epping, J.D.; Pech-Canul, M.I.; Bekheet, M.F.; Gurlo, A. Macroporous polymer-derived $\mathrm{SiO}_{2} / \mathrm{SiOC}$ monoliths freeze-cast from polysiloxane and amorphous silica derived from rice husk. J. Eur. Ceram. Soc. 2017, 37, 4809-4820. [CrossRef]

5. Naviroj, M.; Voorhees, P.W.; Faber, K.T. Suspension- and solution-based freeze casting for porous ceramics. J. Mater. Res. 2017, 32, 3372-3382. [CrossRef]

6. Schwartzwalder, K.; Somers, H.; Somers, A.H. Method of Making Porous Ceramic Articles. U.S. Patent No 3090094, 21 February 1963. 
7. Twigg, M.; Richardson, J. Theory and Applications of Ceramic Foam Catalysts. Chem. Eng. Res. Des. 2002, 80, 183-189. [CrossRef]

8. Twigg, M.V.; Richardson, J.T. Fundamentals and Applications of Structured Ceramic Foam Catalysts. Ind. Eng. Chem. Res. 2007, 46, 4166-4177. [CrossRef]

9. Carstens, S.; Dammler, K.; Scheffler, M.; Enke, D. Reticulated Alumina Replica Foams with Additional Sub-Micrometer Strut Porosity. Adv. Eng. Mater. 2019, 21, 1900791. [CrossRef]

10. Zampieri, A.; Colombo, P.; Mabande, G.T.P.; Selvam, T.; Schwieger, W.; Scheffler, F. Zeolite Coatings on Microcellular Ceramic Foams: A Novel Route to Microreactor and Microseparator Devices. Adv. Mater. 2004, 16, 819-823. [CrossRef]

11. Betke, U.; Lieb, A. Micro-Macroporous Composite Materials-Preparation Techniques and Selected Applications: A Review. Adv. Eng. Mater. 2018, 20, 1800252. [CrossRef]

12. Lee, J.-H.; Choi, H.-J.; Yoon, S.Y.; Kim, B.-K.; Park, H.-C. Processing of porous hydroxyapatite scaffolds containing calcium phosphate glass-ceramics for bone tissue engineering. J. Ceram. Process. Res. 2013, 14, 544-548.

13. Yang, T.Y.; Kim, W.Y.; Yoon, S.Y.; Park, H.C. Macroporous silicate ceramics prepared by freeze casting combined with polymer sponge method. J. Phys. Chem. Solids 2010, 71, 436-439. [CrossRef]

14. Schelm, K.; Fey, T.; Dammler, K.; Betke, U.; Scheffler, M. Hierarchical-Porous Ceramic Foams by a Combination of Replica and Freeze Technique. Adv. Eng. Mater. 2019, 21, 155. [CrossRef]

15. Deville, S. Ice-templating, freeze casting: Beyond materials processing. J. Mater. Res. 2013, 28, 2202-2219. [CrossRef]

16. Deville, S. Freezing Colloids: Observations, Principles, Control, and Use: Applications in Materials Science, Life Science, Earth Science, Food Science, and Engineering; Springer: Cham, Switzerland, 2017.

17. Peter Haseley, G.-W.O. Freeze-Drying; Wiley VCH: Weinheim, Germany, 2018.

18. Deville, S.; Saiz, E.; Tomsia, A.P. Ice-templated porous alumina structures. Acta Mater. 2007, 55, 1965-1974. [CrossRef]

19. Naviroj, M.; Miller, S.; Colombo, P.; Faber, K. Directionally aligned macroporous SiOC via freeze casting of preceramic polymers. J. Eur. Ceram. Soc. 2015, 35, 2225-2232. [CrossRef]

20. Munch, E.; Franco, J.; Deville, S.; Hunger, P.; Saiz, E.; Tomsia, A.P. Porous ceramic scaffolds with complex architectures. JOM 2008, 60, 54-58. [CrossRef]

21. Deville, S.; Saiz, E.; Nalla, R.K.; Tomsia, A.P. Freezing as a Path to Build Complex Composites. Science 2006, 311, 515-518. [CrossRef]

22. Munch, E.; Saiz, E.; Tomsia, A.P.; Deville, S. Architectural Control of Freeze-Cast Ceramics Through Additives and Templating. J. Am. Ceram. Soc. 2009, 92, 1534-1539. [CrossRef]

23. Koch, D.; Andresen, L.; Schmedders, T.; Grathwohl, G. Evolution of Porosity by Freeze Casting and Sintering of Sol-Gel Derived Ceramics. J. Sol-Gel Sci. Technol. 2003, 26, 149-152. [CrossRef]

24. Deville, S.; Maire, E.; LaSalle, A.; Bogner, A.; Gauthier, C.; Leloup, J.; Guizard, C. Influence of Particle Size on Ice Nucleation and Growth During the Ice-Templating Process. J. Am. Ceram. Soc. 2010, 93, 2507-2510. [CrossRef]

25. Hong, S.-J.; Yu, H.-S.; Kim, H.-W. Preparation of porous bioactive ceramic microspheres and In Vitro osteoblastic culturing for tissue engineering application. Acta Biomater. 2009, 5, 1725-1731. [CrossRef] [PubMed]

26. Koh, Y.-H.; Song, J.-H.; Lee, E.-J.; Kim, H.-E. Freezing Dilute Ceramic/Camphene Slurry for Ultra-High Porosity Ceramics with Completely Interconnected Pore Networks. J. Am. Ceram. Soc. 2006, 89, 3089-3093. [CrossRef]

27. Shanti, N.O.; Araki, K.; Halloran, J.W. Particle Redistribution During Dendritic Solidification of Particle Suspensions. J. Am. Ceram. Soc. 2006, 89, 2444-2447. [CrossRef]

28. Singh, G.; Soundarapandian, S. Effect of freezing conditions on $\beta$-Tricalcium Phosphate /Camphene scaffold with micro sized particles fabricated by freeze casting. J. Mech. Behav. Biomed. Mater. 2018, 79, 189-194. [CrossRef] [PubMed]

29. Yoon, B.-H.; Koh, Y.-H.; Park, C.-S.; Kim, H.-E. Generation of Large Pore Channels for Bone Tissue Engineering Using CampheneBased Freeze Casting. J. Am. Ceram. Soc. 2007, 90, 1744-1752. [CrossRef]

30. Yoon, B.-H.; Lee, E.-J.; Kim, H.-E.; Koh, Y.-H. Highly Aligned Porous Silicon Carbide Ceramics by Freezing Polycarbosilane/Camphene Solution. J. Am. Ceram. Soc. 2007, 90, 1753-1759. [CrossRef]

31. Brennan, J.G.; Wüstenberg, T. (Eds.) Food Processing Handbook, 2nd ed.; Wiley-VCH: Weinheim, Germany, 2012.

32. International Organization for Standardization (ISO). Plastics-Methods for Determining the Density of Non-Cellular Plastics: Part 1: Immersion Method, Liquid Pyknometer Method and Titration Method; ICS>83>83.080>83.080.01; ISO: Vernier, Switzerland, 2012.

33. Betke, U.; Dalicho, S.; Rannabauer, S.; Lieb, A.; Scheffler, F.; Scheffler, M. Impact of Slurry Composition on Properties of Cellular Alumina: A Computed Tomographic Study. Adv. Eng. Mater. 2017, 19, 1700138. [CrossRef]

34. Brown, D.D.; Green, D.J. Investigation of Strut Crack Formation in Open Cell Alumina Ceramics. J. Am. Ceram. Soc. 1994, 77, 1467-1472. [CrossRef]

35. Ahmed, Y.M.; Ewais, E.M.; El-Sheikh, S.M. Effect of dispersion parameters on the consolidation of starch-loaded hydroxyapatite slurry. Process. Appl. Ceram. 2014, 8, 127-135. [CrossRef]

36. Almeida, F.; Botelho, E.; Melo, F.; Campos, T.; Thim, G. Influence of cassava starch content and sintering temperature on the alumina consolidation technique. J. Eur. Ceram. Soc. 2009, 29, 1587-1594. [CrossRef]

37. Alves, H.M.; Tari, G.; Fonseca, A.T.; Ferreira, J.M.F. Processing of porous corderite bodies by starch consolidation. Mater. Res. Bull. 1998, 33, 1439-1448. [CrossRef]

38. Gregorova, E.; Zivcova, Z.; Pabst, W.; Stetina, J.; Keupper, M. Rheology of ceramic suspensions with organic or biopolymeric gelling additives: Part III: Suspensions with starch. Ceramics-Silikaty 2008, 52, 250-259. 
39. Gregorová, E.; Pabst, W. Process control and optimized preparation of porous alumina ceramics by starch consolidation casting. J. Eur. Ceram. Soc. 2011, 31, 2073-2081. [CrossRef]

40. Gregorova, E.; Pabst, W.; Stetina, J. Rheology of ceramic suspensions with organic or biopolymeric gelling additives: Part II. Suspensions with carrageenan. Ceramics-Silikaty 2006, 50, 232-238.

41. Ju, C.; Wang, Y.; Ye, J.; Huang, Y. Modified-starch consolidation of alumina ceramics. J. Wuhan Univ. Technol. Sci. Ed. 2008, 23, 558-561. [CrossRef]

42. Talou, M.; Villar, M.; Camerucci, M.; Moreno, R. Rheology of aqueous mullite-starch suspensions. J. Eur. Ceram. Soc. 2011, 31, 1563-1571. [CrossRef]

43. Talou, M.; Camerucci, M. Two alternative routes for starch consolidation of mullite green bodies. J. Eur. Ceram. Soc. 2010, 30, 2881-2887. [CrossRef]

44. Yang, L.; Ning, X.; Bai, Y.; Jia, W. A scalable synthesis of non-agglomerated and low-aspect ratio hydroxyapatite nanocrystals using gelatinized starch matrix. Mater. Lett. 2013, 113, 142-145. [CrossRef]

45. Lyckfeldt, O.; Ferreira, J.M.F. Processing of porous ceramics by 'starch consolidation'. J. Eur. Ceram. Soc. 1998, 18, 131-140. [CrossRef]

46. Mastalska-Popławska, J.; Sikora, M.; Izak, P.; Góral, Z. Applications of starch and its derivatives in bioceramics. J. Biomater. Appl. 2019, 34, 12-24. [CrossRef] [PubMed]

47. Kalemtas, A.; Topates, G.; Aydin, M.T.A.; Özey, N. Starch consolidation of SiC ceramics: Processing and low-temperature sintering in an air atmosphere. J. Asian Ceram. Soc. 2020, 8, 106-115. [CrossRef]

48. Elbadawi, M.; Mosalagae, M.; Reaney, I.; Meredith, J. Guar gum: A novel binder for ceramic extrusion. Ceram. Int. 2017, 43, 16727-16735. [CrossRef]

49. Hareesh, U.N.S.; Anantharaju, R.; Biswas, P.; Rajeswari, K.; Johnson, R. Colloidal Shaping of Alumina Ceramics by Thermally Induced Gelation of Methylcellulose. J. Am. Ceram. Soc. 2011, 94, 749-753. [CrossRef]

50. Schelm, K.; Dammler, K.; Betke, U.; Scheffler, M. Tailoring of the Wetting Behavior of Alumina Dispersions on Polymer Foams by Methylcellulose Addition: A Route Toward Mechanically Stable Ceramic Replica Foams. Adv. Eng. Mater. 2019, $21,1900635$. [CrossRef]

51. Bingham, E.C. Fluidity and Plasticity; Mc Graw-Hill Book Company, Inc.: New York, NY, USA, 1922.

52. Herschel, W.H.; Bulkley, R. Konsistenzmessungen von Gummi-Benzolloesungen. Kolloid-Zeitschrift 1926, 39, 291-300. [CrossRef]

53. Barnes, H.A. A Handbook of Elementary Rheology; University of Wales Institute of Non-Newtonian Fluid Mechanics: Aberystwyth, UK, 2000.

54. Mezger, T.G. The Rheology Handbook, 4th ed.; Vincentz Network: Hannover, Germany, 2014.

55. Meeker, S.P.; Bonnecaze, R.T.; Cloitre, M. Slip and Flow in Soft Particle Pastes. Phys. Rev. Lett. 2004, 92, 198302. [CrossRef] [PubMed]

56. Ostwald, W. Ueber die Geschwindigkeitsfunktion der Viskositaett disperser Systeme. I. Kolloid-Zeitschrift 1925, 36, 99-117. [CrossRef]

57. Adebowale, A.-R.A.; Sanni, L.O. Effects of solid content and temperature on viscosity of tapioca meal. J. Food Sci. Technol. 2011, 50, 573-578. [CrossRef]

58. Hadi, A.; Emadi, R.; Baghshahi, S.; Naghavi, S. Different Pore Size Alumina Foams and Study of their Mechanical Properties. Ceramics-Silikaty 2015, 59, 6-9.

59. Voigt, C.; Aneziris, C.G.; Hubálková, J. Rheological Characterization of Slurries for the Preparation of Alumina Foams via Replica Technique. J. Am. Ceram. Soc. 2015, 98, 1460-1463. [CrossRef]

60. Zhu, X.; Jiang, D.; Tan, S. The control of slurry rheology in the processing of reticulated porous ceramics. Mater. Res. Bull. 2002, 37, 541-553. [CrossRef]

61. Preiss, A.; Su, B.; Collins, S.; Simpson, D. Tailored graded pore structure in zirconia toughened alumina ceramics using double-side cooling freeze casting. J. Eur. Ceram. Soc. 2012, 32, 1575-1583. [CrossRef]

62. Rannabauer, S.; Söffker, G.-M.; Scheunemann, M.; Betke, U.; Scheffler, M. Increased Mechanical Stability and Thermal Conductivity of Alumina Reticulated Porous Ceramics (RPC) by Nanoparticle Infiltration Processing. Adv. Eng. Mater. 2017, 19, 1700211. [CrossRef] 